\title{
GENERALIZED INTEGRAL OPERATORS RELATED WITH $p$-VALENT ANALYTIC FUNCTIONS
}

\author{
KHALIDA INAYAT NOOR AND MUHAMMAD ARIF
}

Abstract. Let $\mathscr{A}(p), p \in N$, be the class of functions $f: f(z)=z^{p}+\sum_{k=1}^{\infty} a_{p+k} z^{p+k}$, analytic in the unit disc $E$. For $n \in N_{0}, n>-p$, an integral operator $I_{n+p-1}: \mathscr{A}(p) \longrightarrow \mathscr{A}(p)$ is defined as $I_{n+p-1} f=f_{n+p-1}^{(-1)} \star f$ such that $\left(f_{n+p-1}^{(-1)} \star f_{n+p-1}\right)(z)=\frac{z^{p}}{(1-z)^{p+1}}$ where $f_{n+p-1}(z)=\frac{z^{p}}{(1-z)^{n+p}}$ and $\star$ denotes convolution. Using this integral operator, some new classes $H_{n, p}(k, \alpha, \beta, \mu, \lambda)$ of $\mathscr{A}(p)$ are introduced and certain interesting properties of these classes are studied. A radius problem is also discussed.

Mathematics subject classification (2000): 30C45, 30C50.

Keywords and phrases: $p$-valent functions, convolution, integral operator, radius problems.

\section{REFERENCES}

[1] A. W. Goodman, Univalent Functions, Vol. I, II, Polygonal Publishing House, Washington, N. J., 1983.

[2] J. LiU AND K. I. NoOR, Some properties of Noor integral operator, J. Nat. Geometry, 21(2002), 81-90.

[3] S. S. MiLler, Differential inequalities and Caratheodory functions, Bull. Amer. Math. Soc., 81(1975), 79-81.

[4] K. I. NooR, On subclasses of close-to-convex functions of higher order, Inter. J. Math. Math. Sci., 15(1992), 279-290.

[5] K. I. NoOR, On new classes of integral operators, J. Nat. Geometry, 16(1999), 71-80.

[6] K. I. NooR, Some classes of p-valent analytic functions defined by certain integral operators, Appl. Math. Computation, 157(2004), 835-840.

[7] K. I. NooR, Generalized integral operator and multivalent functions, J. Inequal. Pure Appl. Math., 6(2005), 1-7, article xx.

[8] K. I. Noor AND M. A. Noor, On integral operators, J. Math. Anal. Appl., 238(1999), 341-352.

[9] S. Ponnusamy, Differential subordination and Bazilevic functions, Proc. Ind. Acad. Sci., 105(1995), 169-186. 